\title{
Molecular medicine of microRNAs: structure, function and implications for diabetes
}

\section{Erica Hennessy and Lorraine O'Driscoll*}

MicroRNAs (miRNAs) are a family of endogenous small noncoding RNA molecules, of 19-28 nucleotides in length. In humans, up to $3 \%$ of all genes are estimated to encode these evolutionarily conserved sequences. miRNAs are thought to control expression of thousands of target mRNAs. Mammalian miRNAs generally negatively regulate gene expression by repressing translation, possibly through effects on mRNA stability and compartmentalisation, and/or the translation process itself. An extensive range of in silico and experimental techniques have been applied to our understanding of the occurrence and functional relevance of such sequences, and antisense technologies have been successfully used to control miRNA expression in vitro and in vivo. Interestingly, miRNAs have been identified in both normal and pathological conditions, including differentiation and development, metabolism, proliferation, cell death, viral infection and cancer. Of specific relevance and excitement to the area of diabetes research, miRNA regulation has been implicated in insulin secretion from pancreatic $\beta$-cells, diabetic heart conditions and nephropathy. Further analyses of miRNAs in vitro and in vivo will, undoubtedly, enable us determine their potential to be exploited as therapeutic targets in diabetes.

Small RNAs are a family of regulatory noncoding RNAs up to 40 nucleotides in length that can induce gene silencing through specific basepairing with target mRNA molecules. Apart from their major function of gene regulation (Ref. 1), small RNAs in plants defend genomes against random integration of transposable elements and attack from invasive nucleic acids such as viruses
(Ref. 2); this mechanism of defence against viral infection may also occur in mammals (Ref. 3). MicroRNAs (miRNAs) represent a major class of these small regulatory RNAs.

Following transcription of miRNA genes, one or two miRNAs can be generated from a single hairpin-loop precursor RNA (Ref. 4), although some precursor molecules are known to contain

National Institute for Cellular Biotechnology, Dublin City University, Dublin 9, Ireland.

*Corresponding author: Lorraine O'Driscoll, National Institute for Cellular Biotechnology, Dublin City University, Dublin 9, Ireland. Tel: +353 1 7005402; Fax: +353 1 7005484; E-mail: lorraine. odriscoll@dcu.ie 
more than six hairpin loops, referred to as miRNA clusters (Ref. 5). miRNAs bind to complementary sequences within the $3^{\prime}$ untranslated region ( $3^{\prime}$ UTR) of their target mRNA transcript and, by virtue of proteins associated with the miRNA, usually direct target cleavage (if there is perfect complementarity with the target), or translational repression without cleavage of target (if partial complementarity with target) (Ref. 6). The 'seed' region (nucleotides 2-7) at the $5^{\prime}$ end of the miRNA is often sufficient for specificity and functionality of the miRNA (Ref. 7).

Hundreds of miRNA genes are predicted to be present in mammals, with each miRNA apparently regulating multiple mRNAs, and multiple miRNAs regulating each mRNA (Refs 8, 9, 10). miRNAs are proposed to be involved in regulating at least a third of all genes within the human genome (Ref. 11) although, of the hundreds of miRNAs identified to date, the biological function(s) of only very few has been elucidated (Ref. 12).

\section{miRNA discovery}

The firstmiRNA, lin-4, wasidentified in 1993 during a genetic screen for mutants that disrupt developmental timing in Caenorhabditis elegans (Ref. 13). The lin-4 gene was shown to produce a pair of small RNAs of approximately 61 and 22 nucleotides in length, with the larger being the precursor of the smaller. Both RNAs contained sequences complementary to sites in the $3^{\prime}$ UTR of lin-14 mRNA, suggesting that lin-4 regulates lin-14 translation by an antisense RNA-RNA interaction (Refs 14, 15). A second C. elegans miRNA, let-7, was discovered in 2000 (Ref. 16); let-7 is also involved in developmental timing and represses expression of the lin- 41 and hbl-1 mRNAs (Refs 17, 18, 19). let-7 and lin-41 are phylogenetically conserved among a wide variety of multicellular organisms, indicating that these small RNAs could represent a general mechanism for post-transcriptional regulation (Ref. 4).

Since these initial discoveries, many miRNAs have been identified in single-celled and multicellular organisms, including plant and mammalian cells (a database of known and predicted endogenous miRNAs is available at http://www.sanger.ac.uk/Software/Rfam/ mirna). Although the exact number of miRNA genes in the human genome has yet to be determined, current estimates range to approximately 800 (http://microrna.sanger.ac. $\mathrm{uk} /$ sequences/). It is thought that many new miRNA genes may have evolved through duplication and mutation, with the number of gene duplications possibly correlating with the level of complexity of the organism (Refs 11, 20). Furthermore, RNA editing (i.e. site-specific modification of an RNA sequence to yield a product differing from that encoded by the DNA template) has been reported in at least $6 \%$ of human miRNAs, which may further increase the diversity of miRNAs and their targets (Ref. 21).

Mammalian miRNA genes are generally transcribed by RNA polymerase (pol) II (Ref. 22). However, recent reports show that human miRNAs mir-515-1, mir-517a, mir-517c and mir519a-1 of the C19MC loci are transcribed by RNA pol III (Ref. 23), and bioinformatic analysis suggests that miRNA sequences containing upstream Alu, tRNA and mammalian-wide interspersed repeat (MWIR) sequences may also be transcribed by RNA pol III (Ref. 23). These transcripts are subsequently capped, polyadenylated and spliced, generating primary miRNA transcripts (pri-miRNAs) (Ref. 24). The pri-miRNAs contain hairpin-loop domains from which mature miRNAs, contained within one arm of the hairpin-loop, are produced. In a limited number of cases a mature miRNA can be produced from either arm of the hairpin-loop; in these events the miRNAs can be named in different ways - for example, mir-458-3p and mir-458-5p, or mir-202 and mir-202* (with the less predominantly expressed miRNA designated by the asterisk) (Ref. 4).

Pri-miRNAs are cleaved by the 'microprocessor complex', which comprises the double-strandedRNA-specific RNase-III-type endonuclease Drosha (RNASEN) and its cofactor DGCR8 (Refs 25, 26, 27) (Fig. 1). DGCR8 apparently functions to recognise the hairpin-loop of primiRNAs and to orientate the catalytic RNase III domain of Drosha to ensure correct cleavage, which releases hairpin-shaped precursor miRNAs (pre-miRNAs) of approximately 70 nucleotides in length (Ref. 28) (Fig. 1). Cleavage by Drosha introduces staggered cuts on each side of the RNA helix stem, resulting in a $5^{\prime}$ phosphate and a two-nucleotide overhang at the $3^{\prime}$ end (Ref. 28). In flies and nematodes, several functional miRNAs have been discovered that bypass the general biogenesis pathway. These 


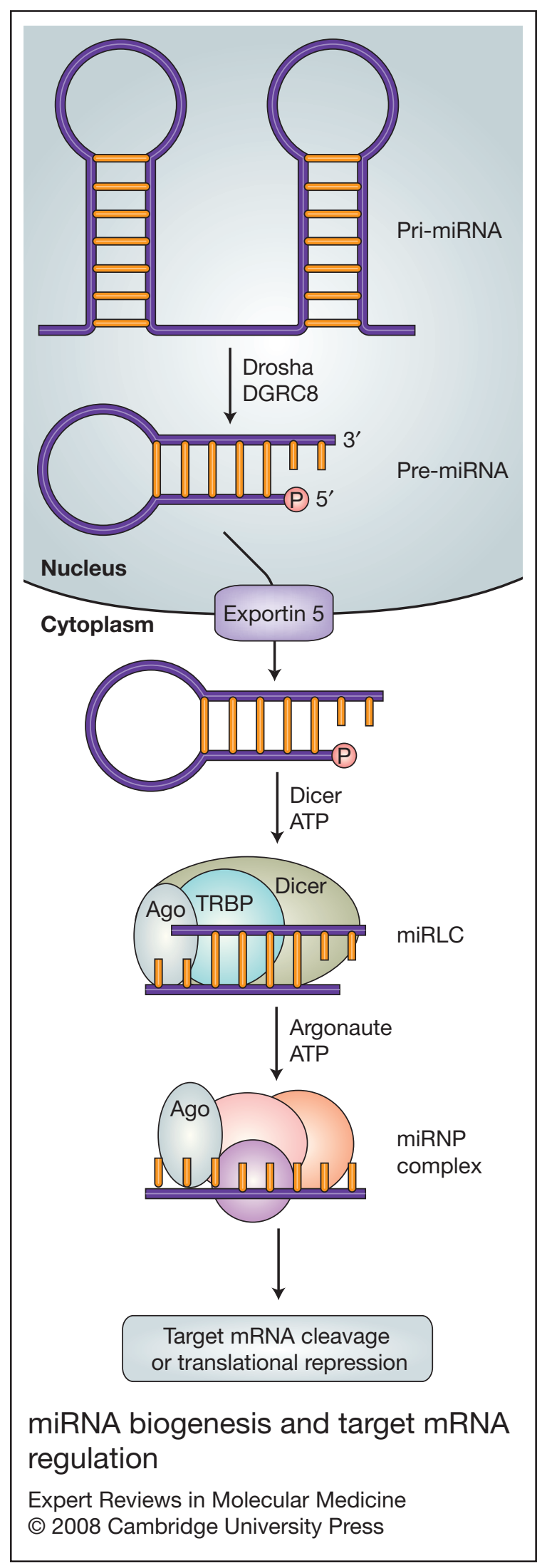

miRNAs, known as 'mirtrons', are generated from spliced intronic sequences and have similar structural characteristics to pre-miRNAs; they enter the traditional miRNA biogenesis pathway at this stage, bypassing Drosha-mediated cleavage (Ref. 29).

Translocation of pre-miRNAs across the nuclear envelope to the cytoplasm is facilitated by the nuclear transport protein exportin-5 (Fig. 1), which recognises the two-nucleotide $3^{\prime}$ overhangs on the pre-miRNA hairpin. Upon arrival in the cytoplasm, pre-miRNAs are cleaved by a second double-stranded-RNAspecific RNAse-III-type endonuclease, Dicer (DICER1) (Fig. 1), which acts in conjunction with a double-stranded-RNA-binding protein partner, transactivation-responsive RNA-binding protein (TRBP/TARBP2P) (Refs 30, 31, 32). In human cells, TRBP recruits argonaute protein (Ago2/ EIF2C2); together Dicer, TRBP and Ago2 form the miRNA RISC loading complex (miRLC; RISC stands for 'RNA-induced silencing complex') (Refs 33, 34). Cleavage of the pre-miRNA by Dicer produces an approximately 22 nucleotide double-stranded miRNA duplex - one strand of

Figure 1. miRNA biogenesis and target mRNA regulation. Primary microRNA (pri-miRNA) generated from transcription in the nucleus is cleaved by Drosha (in conjunction with DGCR8) to generate precursor miRNA (pre-miRNA), which is translocated across the nuclear membrane by the action of exportin 5 . In the cytoplasm, pre-miRNA is cleaved by Dicer with cofactor TRBP (transactivation-responsive RNA-binding protein) and argonaute protein (Ago), which together make up the complex miRLC [miRNA RISC (RNAinduced silencing complex) loading complex] to produce a double-stranded miRNA duplex. This is then unwound by the helicase armitage (not shown), releasing single-stranded mature miRNA. Mature miRNA becomes assembled into miRNPs (miRNA-containing ribonucleoprotein particles), which always include an argonaute protein. A number of other proteins may be - but are not always - involved in miRNP function; these include gemin3, gemin4, vasa intronic gene product $(\mathrm{VIG})$, fragile-X-related protein ( $\mathrm{dFXR}$ ), tudor-SN, fragile $\mathrm{X}$ mental retardation protein (FMRP) and survival of motor neuron protein (SMN). miRNA guides miRNP to its mRNA target and, depending on the level of complementarity, can initiate cleavage or translational repression of mRNA target (see Fig. 2). 
which will become the mature miRNA. The duplex is then unwound by the DEAD-box helicase armitage, releasing the single-stranded mature miRNA (Refs 35, 36).

The Ago2-bound mature miRNA then becomes assembled into effector complexes termed miRNAcontaining ribonucleoprotein particles (miRNPs) (Ref. 37) (Fig. 1). Several forms of miRNPs exist that differ in size and composition, but each form of miRNP contains a member of the argonaute protein family. The major function of miRNAs is to guide the miRNP complex to its target mRNA, where its associated argonaute protein mediates the effect (Ref. 38). Several other miRNP components have been identified, including gemin3 (DDX20), gemin4, vasa intronic gene product (VIG), fragile-X-related protein (dFXR), and the tudor staphylococcal-nucleasedomain-containing protein (tudor-SN) (Refs 39, 40). Gemin3 is a putative DEAD-box RNA helicase, which may function in the unwinding of the mRNA target (Ref. 35), but the precise role of the other proteins in RNA-silencing events remains unclear. Although miRNAs function primarily in the cytoplasm, one miRNA, mir-29b has been found to localise in the nucleus; this is likely due to a hexanucleotide terminal motif in the $3^{\prime}$ region that directs the mature miRNA to be imported back into the nucleus after it is processed in the cytoplasm (Ref. 41).

\section{Mechanism(s) of miRNA action}

In mammals, miRNAs usually exhibit partial complementarity with their mRNA targets; perfect or near-perfect base pairing is quite rare in these organisms, but is predominantly found in plant miRNAs. Partial complementarity of miRNA to mRNA usually leads to translational inhibition (Ref. 42), although animal miRNAs can also induce target degradation despite the lack of perfect complementarity (Refs $43,44,45$ ). Several proposed models exist for the mechanism of translational repression, including miRNAs repressing translation at both pre-initiation and post-initiation stages (Fig. 2), and effects on mRNA stability (decapping and deadenylation) and compartmentalisation into translationally repressive sites (Fig. 2); it still remains to be deciphered which of these model mechanisms are cause and consequence of translational repression.

miRNAs affecting initiation steps only affect capdependent translation, possibly through $\mathrm{m}^{7} \mathrm{G}$ cap recognition (Refs 46, 47, 48, 49, 50). Argonaute proteins contain structural similarities to the cap-binding protein eIF4E, and thus it has been suggested that translational repression may occur due to competition between argonaute and eIF4E for binding to the cap structure (Ref. 51) (Fig. 2a). Argonaute proteins are also thought to recruit eIF6, which binds to the large ribosomal subunit, preventing binding of the small subunit and thus inhibiting mRNA translation (Ref. 52) (Fig. 2a).

Much evidence also exists for post-initiation mechanisms of repression, which affect both cap-dependent and cap-independent translation (Ref. 53). Polysome profile experiments indicate that, under conditions of translational repression, target mRNAs are fully loaded with ribosomes (Refs 15,54), a number of which are engaged in active translation (Ref. 53), suggesting that translation initiation and elongation phases are not compromised. Two possible theories were suggested to explain these findings. The ribosome 'drop-off' theory suggests that ribosomes engaged in translation of miRNA-associated mRNAs are prone to terminate translation prematurely (Fig. 2b). Alternatively, association of active ribosomes with repressed mRNAs could also be explained by the ability of miRNP complex to recruit proteolytic enzymes to degrade the nascent polypeptide as it emerges from the ribosome (Ref. 15) (Fig. 2b). Conflicting evidence exists on the role of proteolytic enzymes in miRNA function, as targeting of reporter proteins and the use of proteinase inhibitors have shown no effect on translational repression (Refs 50, 53).

miRNAs are apparently also involved in regulating mRNA stability and induction of decay of repressed mRNA targets. Argonaute proteins, miRNAs and their repressed target mRNAs have recently been shown to be compartmentalised in cytoplasmic foci called P-bodies (Refs 50, 55, 56, 57, 58, 59). These are sites of translational repression and mRNA decay; they are rich in factors associated with these processes, and are lacking in ribosomes or any other factors associated with translation initiation (Ref. 60). It is proposed that P-body proteins may participate in the formation of a repressive complex on the target mRNA, which could eventually lead to mRNA aggregation into P-bodies (Ref. 61). Within P-bodies, miRNA/ mRNA-bound argonaute protein recruits GW182 protein (TNRC6A), which subsequently recruits 


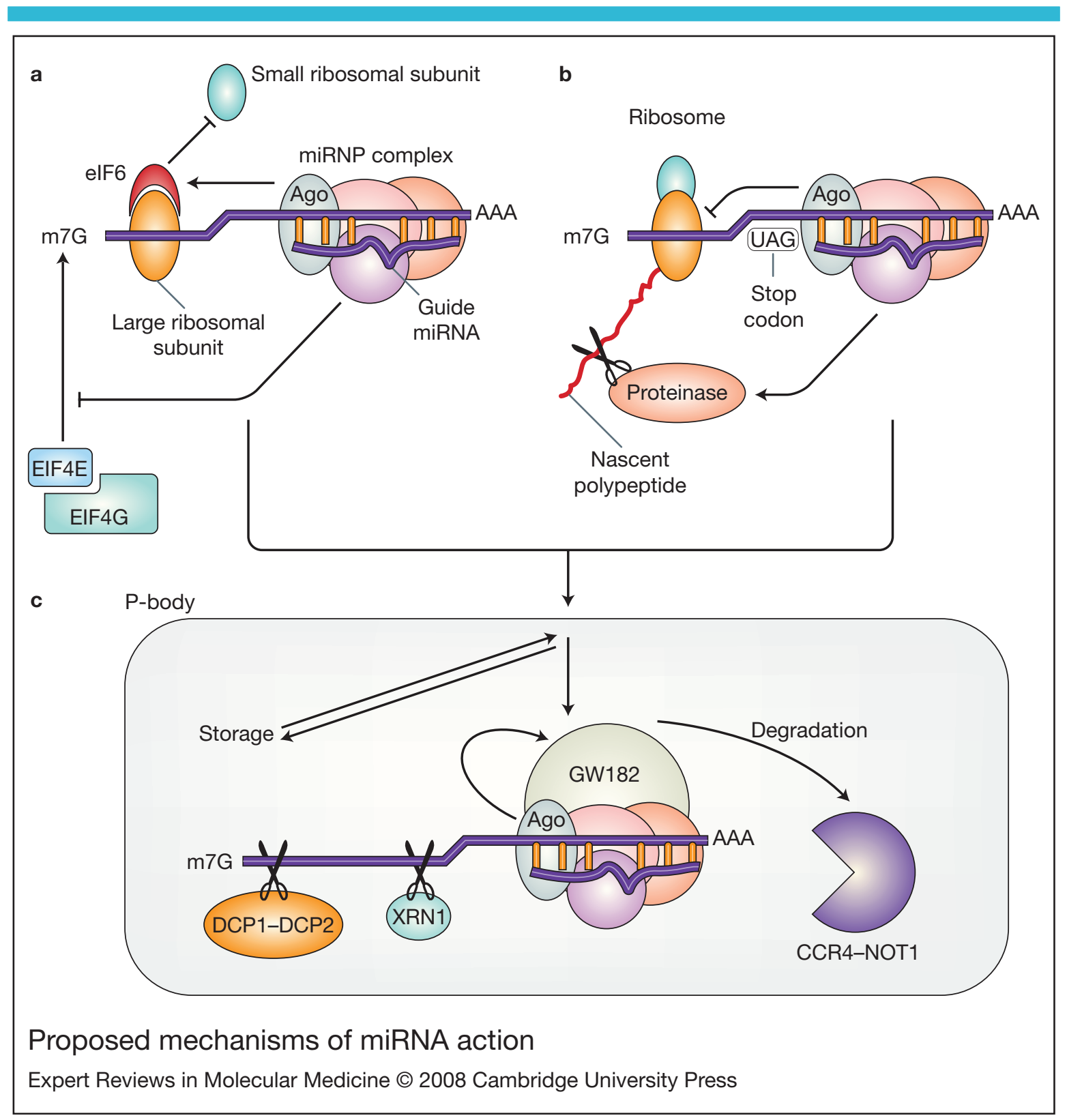

Figure 2. Proposed mechanisms of miRNA action. MicroRNAs (miRNAs) can inhibit translation at pre- and post-initiation stages. (a) At pre-initiation stages, the miRNP complex may affect $\mathrm{m}^{7} \mathrm{G}$-cap-dependent translation through competition of the argonaute protein with the elF4G initiation complex for binding to the cap structure; argonaute proteins also recruit elF6, which prevents large ribosomal subunit binding to the small subunit. (b) At postinitiation stages, miRNPs may cause ribosomes to terminate translation prematurely, generating truncated polypeptides, or recruit proteolytic enzymes that degrade the polypeptide chain as it emerges from the ribosome. Repressed mRNAs arising from these models can then be transported to P-bodies for storage or degradation: the miRNP complex recruits GW182 protein; the latter subsequently recruits deadenylase enzyme CCR4-NOT1; the mRNA is then decapped by DCP1-DCP2, and degraded by exonuclease activity of XRN1.

deadenylating enzyme CCR4-NOT1 (CNOT1), and this is followed by mRNA decapping by DCP1-DCP2 enzyme - thereby affecting stability of repressed mRNA. Repressed mRNAs are then degraded by $5^{\prime}$ to $3^{\prime}$ exonuclease activity of XRN1 (5'-exoribonuclease 1) (Refs 43, $55,57,62,63$ ) (Fig. 2c). In addition to facilitating mRNA degradation, P-bodies may function as 
temporary storage sites for repressed mRNAs; once protein synthesis has been stimulated, repressed mRNAs may re-enter translation (Ref. 64).

Although miRNAs generally negatively regulate their target mRNAs, miRNA-associated proteins can play a role in AU-rich element (ARE)-mediated translational activation of tumour necrosis factor $\alpha$ (Ref. 65). The miRNAs mir-369-3 and let-7 function in the recruitment of these proteins to the ARE sites in a sequencespecific manner (Ref. 66). It is thought that miRNAs function in translation activation under the quiescence phase of the cell cycle and translation inhibition during the proliferation phase of the cell cycle (Ref. 67), although the mechanisms of miRNA-mediated translation activation remain unclear. mir-122 has also been shown to enhance replication of hepatitis C virus, but it is unclear whether this occurs by similar mechanisms of ARE activation (Ref. 68).

\section{Technologies for miRNA identification and analysis}

Both computational prediction and experimental analysis have been used successfully to identify and analyse miRNAs.

Computational analysis (e.g. applying MirScan software) involves candidate miRNA prediction, based on known structural features, followed by experimental analysis to validate the existence of the predicted sequence (Ref. 69). Computational approaches have greatly contributed to miRNA target analysis. Based on the realisation that the 'seed' nucleotides within the $5^{\prime}$ region of miRNAs are of significant functional relevance, bioinformatics approaches have been developed and applied to predict direct targets of specific miRNAs, by searching for seed complementarity in mRNA 3' UTRs (Refs 70, 71, 72, 73, 74, 75, 76, 77). As a result of the short seed sequence (nucleotides 2-7), numerous potential mRNA targets are generally predicted for each miRNA. Binding studies and functional analysis are necessary to determine true mRNA targets.

Experimental analysis involves the identification of a small RNA sequence, followed by bioinformatic analysis to determine if this sequence fulfils the defined structural characteristics of a miRNA (Refs 78, 79). De novo identification of miRNAs generally involves sequencing of size-fractioned cDNA libraries. To achieve this, small RNAs (approximately 20-28 nucleotides) are isolated from denaturing gels and, following attachment of $5^{\prime}$ and $3^{\prime}$ adapters to the RNAs, reversetransciptase (RT)-PCR is performed. The resulting cDNAs are cloned to form a cDNA library. Individual clones are subsequently sequenced to establish the genomic origin of the small RNA.

In addition to identifying new miRNAs, largescale cDNA cloning may be used to evaluate the relative expression levels of miRNAs in a range of specimens. However, global profiling of miRNAs most frequently utilises microarrays (Refs 9, 80, $81,82,83,84,85,86,87,88,89,90,91)$ or the RNA-primed array-based Klenow enzyme (RAKE) assay (Ref. 92). TaqMan low-density microarrays (TLDAs) have proven popular for such studies (http://www.appliedbiosystems. com/index.cfm). Bead-based flow cytometry assays have also been developed for miRNA analysis, whereby beads are coupled to probes $(<100$ probes) representing individual miRNAs. Following incubation with the specimen of interest, the beads are analysed by flow cytometry for identification and quantification of expressed miRNAs (Ref. 93). Methods used for validation of results from global analysis - or for analysis of small numbers of miRNAs include qRT-PCR, northern blotting, dot blotting, RNase protection assay, and a modified invader assay (Refs 94, 95).

The functional relevance of miRNAs may be investigated using pre-miRNAs $\left(\right.$ Pre-miR ${ }^{\mathrm{TM}}$ miRNA precursors) or miRNA inhibitors (Anti$\mathrm{miR}^{\mathrm{TM}}$ miRNA inhibitors) (see http://www. ambion.com). Antisense technologies have also been used successfully to regulate miRNA levels in vitro and in vivo (Refs 96, 97, 98). Simultaneous expression of multiple miRNAs by RNA pol III is being investigated, as RNA pol III can achieve higher expression levels compared with expression driven by RNA pol II; as miRNA-mediated mRNA silencing is dosedependent, this mechanism would possibly increase the chances of producing hypomorphic phenotypes (Ref. 99).

\section{miRNAs in normal and pathological conditions}

miRNAs have been implicated in regulation of cellular processes such as differentiation (Ref. 100), proliferation, apoptosis (Ref. 101), metabolism (Ref. 102), haematopoiesis (Ref. 103), 
cardiogenesis (Ref. 104), morphogenesis and insulin secretion (Ref. 105), in addition to acting in several feedback loops involved in signal transduction pathways (Ref. 106). miRNAs are vital for cell survival: elimination of miRNA maturation by Dicer knockout leads to embryonic lethality in mice (Ref. 107). miRNAs are involved in such a wide variety of cellular processes that it is likely their dysregulation or abnormal expression could lead to a range of disease states. miRNAs have already been implicated in the pathogenesis of several human diseases, such as neurological disorders, cancer, and viral and metabolic diseases (Ref. 98).

\section{Neurological disorders}

Spinal muscular atrophy (SMA), a progressive neurodegenerative disease, is caused by deletion or loss of function mutations in the SMN (survival of motor neuron) protein (Ref. 108). SMN is a component of the miRNP complex that performs the effector functions of the miRNA pathway (Ref. 37). Fragile X syndrome is caused by inactivation of the gene FMR1, and hence silencing of the fragile $X$ mental retardation protein (FMRP), which is also associated with miRNP complex formation (Ref. 109). These studies indicate that disruptions in the miRNP machinery and hence miRNA activity can lead to disease states. Tourette syndrome is associated with a single-nucleotide polymorphism (SNP) in the $3^{\prime}$ UTR of the SLITRK1 gene, which is the binding site of mir-189; this SNP hence modifies the interaction of mir-189 (Ref. 110). In addition, mir-134 regulation of LIMK1 in hippocampal neurons controls spine development and possibly also contributes to synaptic development, maturation and plasticity (Ref. 111); thus, dysregulation of mir-134 could potentially lead to complications in these processes.

\section{Cancer}

Many miRNA genes are thought to reside at chromosomal breakpoints or fragile sites associated with cancer (Ref. 112). The mir-15/16 cluster is located at one such site and is deleted in the majority of $\mathrm{B}$ cell chronic lymphocytic leukaemias (B-CLLs) (Ref. 113), as well as mantle cell lymphomas and prostate cancers (Ref. 114), suggesting that mir-15/16 may function as tumour suppressors. Members of the let-7 family also located at fragile sites (Ref. 112) are frequently deleted in cancer patients, leading to elevated levels of the oncogene product RAS (Ref. 115). Some miRNAs have also been shown to possess oncogenic potential; the mir-17-92 cluster, which contains six miRNAs, is located at a chromosome site that is amplified in a range of cancers and overexpression leads to accelerated tumour development in mouse B cell lymphoma models (Ref. 5). Overexpression of the individual miRNAs from the cluster did not reveal the same oncogenic potential, indicating that interaction between a range of miRNAs could be necessary for the development of disease phenotypes. mir-155, which is elevated in Burkitt lymphoma, also acts as an oncogene, with overexpression in B cells leading to development of pre-B-cell lymphomas (Ref. 116). These putative miRNA tumour suppressors and oncogenes represent a potential set of miRNA therapeutic targets. Microarray profiling of miRNAs in tumour tissues and cell lines has identified miRNA differentially expressed in different tumour types, indicating potential use of tumour miRNA profiling in cancers for prediction of developmental lineage, differentiation state, and prognosis (Ref. 93).

\section{Viral disease}

Host mir-32 expression restricts infection of the primate foamy virus 1 (PFV-1), with inhibition of mir-32 leading to doubling of the PFV-1 proliferation rates in host cells (Ref. 117). PFV-1 encodes the Tas protein, which is known to be a suppressor of RNA silencing (Ref. 117), thereby removing the growth limitation inflicted by mir-32 by disrupting the silencing machinery. Many viruses encode similar suppressors of RNA silencing - for example, the Tat protein from human immunodeficiency virus 1 (HIV-1) (Ref. 118) and the B2 protein from Nodamura virus (Ref. 119).

miRNAs represent an efficient mechanism for viruses to use to manipulate host machinery, as they require less space on the viral genome than alternative protein products. Viral miRNAs can target both viral and host mRNAs for repression. Twelve miRNAs from the Karposi sarcoma-associated herpesvirus (KSHV) genome expressed in cells led to the downregulation of a number of genes including thrombospondin 1 (THBS-1), which is a known tumour suppressor and antiangiogenic factor. It is thought that these KSHV miRNAs may contribute directly to pathogenesis of KSHV by 
downregulation of THBS-1 (Ref. 120). The simian virus 40 (SV40) encodes a miRNA that is perfectly complementary to transcripts coding viral $\mathrm{T}$ antigens, leading to their degradation (Ref. 121). This destruction of viral $\mathrm{T}$ antigens aids the virus in evading immune detection by the host. The hepatitis $\mathrm{C}$ virus (HCV) enchances replication via a novel interaction of abundantly expressed mir-122 with the $5^{\prime}$ UTR of the viral genome (Ref. 68). Interferons (IFNs) are key molecules involved in eliciting the antiviral response once an infection has been detected (Ref. 122). IFN- $\beta$ has recently been implicated in the activation of several miRNAs in mammals that have antiviral properties against HCV (Ref. 123), and treatment also leads to reduced mir-122 expression (Ref. 123), which limits HCV replication (Ref. 68). These studies identify a number of different miRNAs that could be therapeutically targeted to hinder viral infection, aid host detection of infection, and prevent viral manipulation of host machinery.

\section{miRNAs relevant to diabetes}

Diabetes mellitus is a metabolic disorder in which insulin either is not secreted in sufficient amounts from $\beta$-cells or does not efficiently stimulate its target cells. Despite high glucose levels, cells starve, as a result of impaired glucose entry into cells. Current treatments for diabetes cannot efficiently control glycaemic levels, resulting in episodes of hyper- and hypoglycaemia (Ref. 124), which increases the possibility of developing secondary complications such as retinopathy, nephropathy and neuropathy (Ref. 125). In the search for more-targeted molecular therapies, miRNAs implicated in insulin secretion and diabetic complications have recently attracted attention.

\section{miRNAs associated with $\beta$-cell insulin secretion}

Recent experimental work has revealed a limited number of miRNAs - including mir-375, mir$124 \mathrm{a}$ and mir-9 - associated with various subcellular events involved in glucose-stimulated insulin secretion (GSIS) (Refs 126, 127, 128). In addition, bioinformatic analysis has indicated potential miRNA target sites in a range of other mRNAs encoding proteins involved in exocytosis - including VAMP2 (vesicle-associated membrane protein 2), SNAP25 (synaptosomalassociated protein $25 \mathrm{kDa}$ ), syntaxin-1, Rab27a (member of the RAS oncogene family), granuphilin (SYTL4) and MyRIP (myosin VIIA and Rab interacting protein). Some miRNAs (mir153, mir-1, mir-133, mir-200 and mir-34) have predicted target sites in several of these functionally related genes (e.g. mir-153 and mir-1 have putative target sites in VAMP2 and SNAP25) (Ref. 129). Although the miRNA target sites identified by bioinformatics have yet to be experimentally validated, this gives an insight into the potential extent of complex networking of molecules involved in exocytosis regulation.

\section{mir-375}

Selective cloning of small RNAs 21-23 nucleotides in length from the $\beta$-cell line MIN-6 and the $\alpha$-cell line TC1 led to the identification of mir-375, a miRNA specific to pancreatic islet cells. Gainand loss-of-function experiments on mir-375 indicated it was involved in GSIS in $\beta$-cells, with overexpression resulting in reduced GSIS and, conversely, knockout of expression resulting in enhanced GSIS (Ref. 105). mir-375 apparently acts on the later stages of exocytosis to reduce insulin secretion.

Based on sequence information, myotrophin has been confirmed as a target of mir-375 action (Table 1); mir-375 mediates repression via a single target site in the $3^{\prime}$ UTR of the myotrophin mRNA (Ref. 105). Myotrophin is involved in vesicle transport in neurons and in neurotransmitter release but its function in pancreatic $\beta$-cells has not been clearly defined (Refs 130, 131, 132). Myotrophin (via its three consecutive ankyrin repeats) interacts with the capping protein $\mathrm{CP}$ (also known as CapZ or $\beta$ actinin). This myotrophin-CP interaction inhibits CP-regulated actin polymerisation (Ref. 133), thereby allowing access of secretory granules to exocytotic site (Fig. 3a). Myotrophin also acts in the nucleus as a transcription factor to activate nuclear factor $\kappa \mathrm{B}(\mathrm{NF}-\mathrm{\kappa B})$, a critical component in maintaining GSIS in $\beta$-cells (Refs 134, 135) (Fig. 3a). It is not yet clear whether mir-375-induced inhibition of myotrophin translation and the corresponding reduction of GSIS are mediated by the $\mathrm{CP}$ or NF-кB pathway, or a combination of both. Myotrophin is also the predicted target of repression for two other miRNAs: mir124 and let-7b (Ref. 136). The function of let-7b in GSIS of $\beta$-cells still remains to be established. 
Table 1. miRNAs implicated in $\beta$-cell insulin secretion and diabetic complications, and their mRNA targets

\begin{tabular}{|c|c|c|c|}
\hline Process/condition & miRNA $^{a}$ & Target mRNA & Ref. \\
\hline \multirow[t]{3}{*}{$\beta$-Cell insulin secretion } & mir-375 & Myotrophin & 105 \\
\hline & mir-124a & $\begin{array}{l}\text { FOXA2 } \\
\text { CREB-1 } \\
\text { Rab27A }\end{array}$ & $\begin{array}{l}138 \\
138 \\
149\end{array}$ \\
\hline & mir-9 & OC2 & 152 \\
\hline Diabetic kidney glomeruli & mir-192 & SIP-1 & 166 \\
\hline Diabetic heart & mir-133 & HERG & 175 \\
\hline \multicolumn{4}{|c|}{ 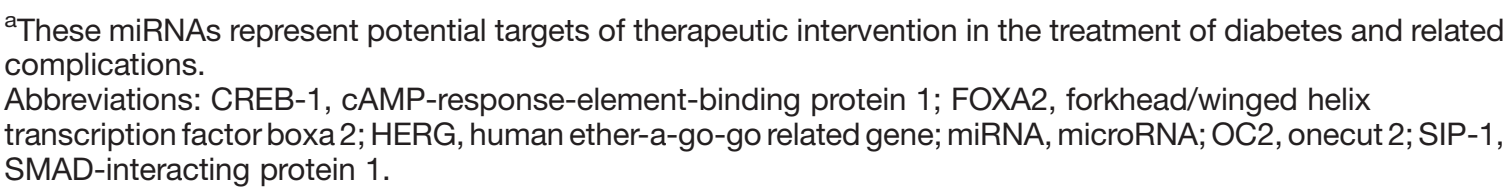 } \\
\hline
\end{tabular}

More recently, knockdown of mir-375 in zebrafish embryos has revealed a role for this miRNA in pancreatic islet development (Ref. 137). When morpholino oligonucleotides were injected into one-cell-stage embryos, resulting in a knockdown of mir-375 activity during the first four days of development, insulin staining showed the formation of an islet at $24 \mathrm{~h}$ post fertilisation but by day 3 the islet had fallen apart and insulin-positive cells were scattered (Ref. 137). The original formation of an islet at $24 \mathrm{~h}$ suggests that mir-375 expression is not essential in early endocrine formation, but more so for maintenance of tissue identity at a later stage. It has not yet been deciphered whether this scattered islet phenotype occurs as a result of mir-375 action on myotrophin expression or whether other mir-375 targets are involved.

\section{mir-124a}

Mir-124a exists in three different isoforms - mir124a1, 2 and 3 - encoded on chromosome 14, 3 and 2, respectively, in the mouse genome. The isoform mir-124a2 is differentially expressed during pancreas development, with a sixfold upregulation at embryonic stage e18.5 compared with e14.5 (Ref. 138). e18.5 is the critical stage for $\beta$-cell differentiation, indicating that mir-124a2 might be significant in this process.

Using PicTar (http://pictar.bio.nyu.edu/ cgi-bin/PicTar) (Ref. 136) and miRanda (http:// www.microrna.org/mammalian/index_new.html) (Ref. 139) bioinformatics tools, the forkhead/ winged helix transcription factor boxa2 (FOXA2) mRNA was identified as a potential target of mir-124a (Table 1). This relationship was subsequently confirmed by over- and underexpression of mir-124a2 in MIN6 murine pancreatic $\beta$-cells, using Pre-Mir and Anti-Mir technology (Pre-miR ${ }^{\mathrm{TM}}$ miRNA precursors and Anti-miR ${ }^{T M}$ miRNA inhibitors; see http://www. ambion.com). CREB-1 (cAMP-response-elementbinding protein), a stimulus-inducible transcription factor, was also predicted as a potential target of mir-124a regulation, and mir$124 \mathrm{a} 2$ over- and underexpression correspond with decreasing and increasing levels of CREB-1, respectively (Ref. 138) (Table 1). As FOXA2 is a target of CREB-1 regulation (Ref. 140), this suggests that FOXA2 expression may be regulated by mir-124a2 directly as well as indirectly (via CREB-1) (Fig. 3b).

FOXA2 is an upstream regulator of the homeobox protein PDX-1 (Refs 141, 142). PDX-1 is essential for $\beta$-cell differentiation, glucose homeostasis and pancreas development (Refs 143, 144) (Fig. 3b), and the human orthologue (insulin promoter factor; IPF1) is mutated in a proportion of early-onset type 2 diabetic patients (Ref. 145). Manipulation of FOXA2 expression, by overexpression or inhibition of mir-124a2, corresponds with a decrease and increase in PDX-1 mRNA levels, respectively (Ref. 138). PDX-1 
a Possible miRNA inhibition of insulin secretion via myotrophin

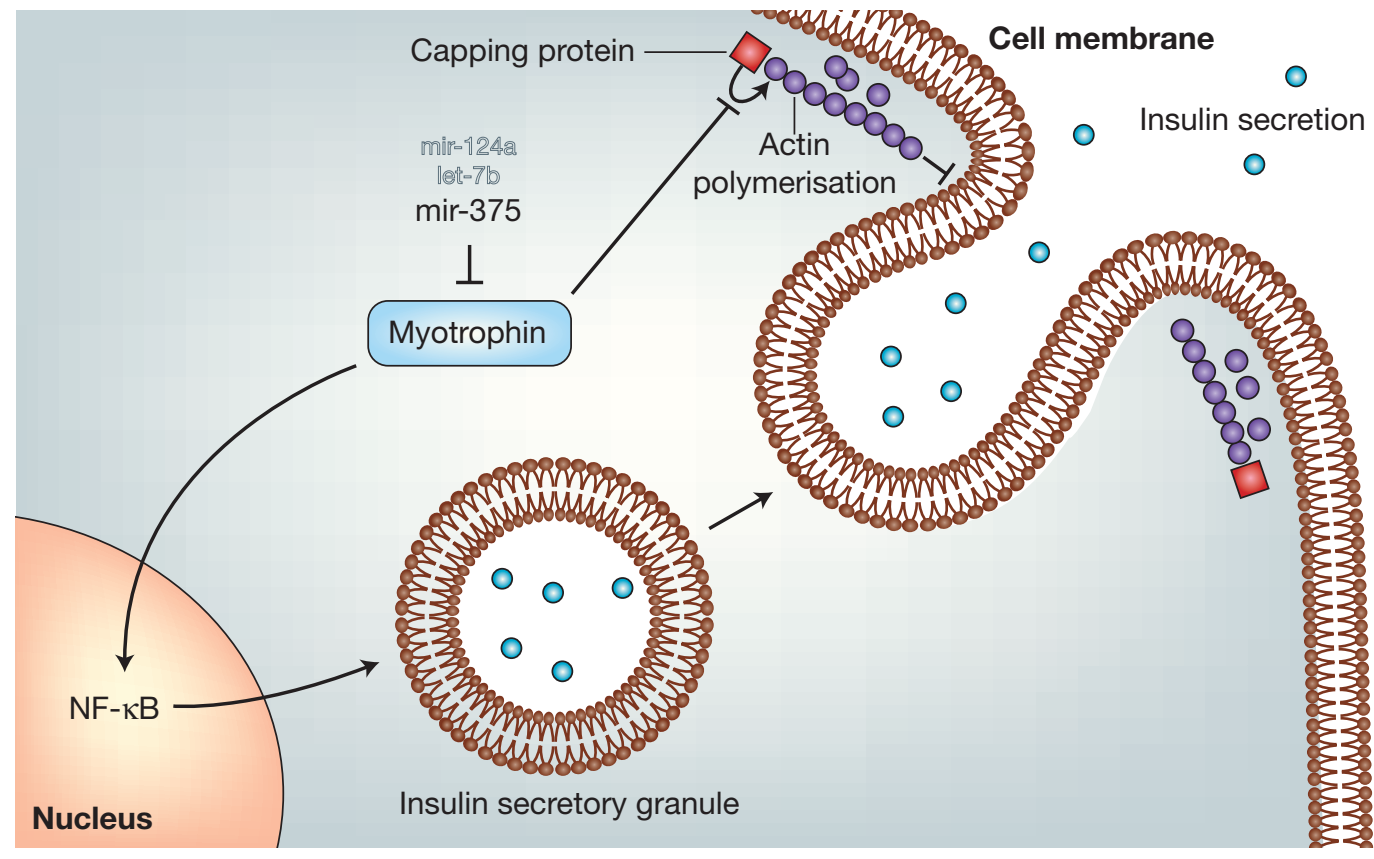

b Possible mir-124a involvement in glucose homeostasis

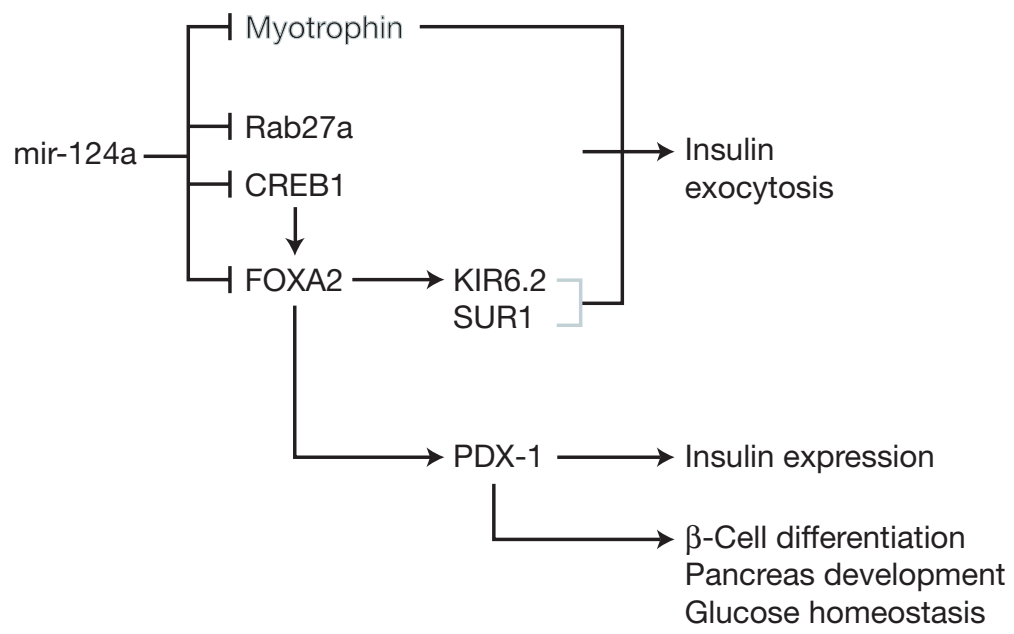

\section{Co-ordinated regulation of insulin exocytosis by miRNAs}

Expert Reviews in Molecular Medicine (c) 2008 Cambridge University Press

Figure 3. Co-ordinated regulation of insulin exocytosis by miRNAs. (See next page for legend.)

regulates expression of the insulin gene; consequently, overexpression and inhibition of mir-124a2 leads to a decrease and increase in insulin mRNA levels, respectively (Ref. 138).

Further downstream targets of FOXA2 regulation are the $\mathrm{K}_{\mathrm{ATP}}$ channel subunits SUR1 (sulphonylurea receptor 1) and KIR6.2 (inward rectifier $\mathrm{K}^{+}$channel member 6.2) (Ref. 146), which are critical for regulated insulin release; mutations in either of these genes can lead to persistent hyperinsulinaemic hypoglycaemia of infancy (PHHI) in humans (Ref. 147). 
Figure 3. Co-ordinated regulation of insulin exocytosis by miRNAs. (Legend; see previous page for figure.) (a) Possible microRNA (miRNA) inhibition of insulin secretion via myotrophin. Overexpression of the myotrophintargeting miRNA mir-375 results in reduced glucose-stimulated insulin secretion, which can be explained through cytoplasmic and/or nuclear actions of myotrophin. Myotrophin interacts with capping protein to inhibit actin polymerisation. Inhibition of actin polymerisation allows access of insulin granules to the cell membrane for exocytosis. In addition, myotrophin interacts with transcription factor NF- $\mathrm{kB}$, which controls expression of several genes critical for glucose-stimulated insulin secretion. Myotrophin also contains putative binding sites for the miRNAs let-7b and mir-124a. (b) Possible mir-124a involvement in glucose homeostasis. Mir-124a targets Rab27a and also FOXA2 (directly and indirectly via CREB1). Myotrophin has also been identified as a potential mir-124a target. FOXA2 may influence several targets relevant to diabetes via PDX-1, including insulin mRNA levels and possibly also $\mathrm{K}_{\text {ATP }}$ channel subunits KIR6.2 and SUR1 (involved in regulated insulin release). It also plays a role in $\beta$-cell differentiation, pancreas development and glucose homeostasis.

Overexpression of mir-124a2 leads to increased $\mathrm{Ca}^{2+}$ levels within the cell (Ref. 138). Knockdown of the SUR1 and KIR6.2 subunits results in impaired $\mathrm{K}_{\mathrm{ATP}}$ channels, causing a build-up of $\mathrm{K}^{+}$ions within the cell, which stimulates opening of voltage-gated calcium channels, thereby allowing $\mathrm{Ca}^{2+}$ ions to enter the cell (increased $\mathrm{Ca}^{2+}$ ions usually stimulate exocytosis). Thus, reduced expression of $\mathrm{K}_{\mathrm{ATP}}$ channel subunits could explain the increase in cytosolic free $\mathrm{Ca}^{2+}$ concentrations following transfection with mir-124a2. FOXA2 deficiency in mice leads to loss of GSIS and excessive insulin release in response to amino acid stimuli (Ref. 146). However, mir-124a2-induced reduction in FOXA2 levels has not shown as dramatic an effect on GSIS as seen in the FOXA2-null mouse (Ref. 138).

Rab27A, which is also involved in GSIS (Ref. 148), has recently been shown to be the target of mir-124a action via a binding site in the 3' UTR of Rab27A mRNA (Ref. 149). Mir$124 a$ also indirectly regulates expression of several other components of the exocytotic machinery in MIN6-B1 cells, including SNAP25, Rab3A, synapsin 1A (SYN1) and NOC2 (nucleolar complex associated 2) (Ref. 149). Overexpression of mir-124a in these cells leads to reduced GSIS. In the same study, mir-96 was identified as a regulator of granuphillin and NOC2, and its expression in MIN6-B1 cells leads to a reduction in stimulated insulin secretion (Ref. 149).

\section{mir-9}

Mir-9 is expressed predominately in neurons in both human and mouse models (Refs 150, 151), and to a lesser extent in pancreatic $\beta$-cells in rat and mouse models (Ref. 152). Onecut2 transcription factor (OC2), which negatively regulates granuphilin (also known as SLP4/ SYTL4) expression, has been identified as a mir-9 target (Table 1). A basal level of mir-9 expression is needed to maintain optimum onecut2 expression levels for normal $\beta$-cell function (Ref. 152), but mir-9 overexpression in rat INS-1E $\beta$-cells leads to a reduced GSIS in these cells (Ref. 152).

Granuphilin associates with insulin secretory granules (Ref. 153) and promotes targeting of these granules to the plasma membrane (Ref. 154); however, it is a negative modulator of exocytosis as it imposes a constraint to inhibit fusion until the correct signals are received by the cell (Ref. 154). Overexpression of mir-9 leads to increased levels of granuphilin expression due to the removal of the repressive effects of onecut2 on the granuphilin promoter (Ref. 152), and hence reduced GSIS is observed as a result of its negative effects on exocytosis. Granuphilin-null mice also show impaired GSIS, with reduced quantity of insulin granules docked to the $\beta$-cell membrane, and conversely exhibit increased insulin exocytosis in response to stimulus (Ref. 155).

Binding partners of granuphilin include the GTP-binding proteins Rab3/Rab27, the SNAREbinding protein Munc-18 and the tSNARE protein syntaxin-1, which are involved in exocytosis of secretory granules in pancreatic $\beta$-cells (Refs 152, 156, 157). mir-9-induced reduction of exocytosis does not occur through manipulation of Rab3, Rab27 and SNARE proteins such as SNAP25, VAMP-2 and syntaxin-1, as the expression levels of these key exocytosis proteins are unchanged in mir-9transfected cells relative to control cells (Ref. 152). However, it is as yet unknown whether the mir-9-mediated reduction of secretagoguestimulated exocytosis via granuphilin occurs 
through downstream manipulation of Munc-18 activity. The effect of granuphilin on Munc-18 is not alone sufficient to mediate such a profound knockdown of stimulus-induced exocytosis (Ref. 156), suggesting that granuphilin and possibly mir-9 have additional targets that participate in this process.

\section{miRNAs associated with diabetic kidney glomeruli}

Diabetic nephropathy - generally defined as urinary albumin excretion of $>300 \mathrm{mg}$ per $24 \mathrm{~h}$ or abnormal renal function characterised by abnormality in serum creatinine, creatinine clearance, or glomerular filtration rate - is the most common cause of kidney failure in patients with diabetes. The abnormal renal function is thought to arise largely from accumulation of extracellular matrix (ECM) proteins in the mesangial cells, hypertrophy of glomerular and tubular elements, and thickening of the glomerular and tubular basement membranes (Refs 158, 159).

ECM proteins such as collagen $1 \alpha 1$ and $1 \alpha 2$ are positively regulated by transforming growth factor $\beta$ (TGF- $\beta$ ), which is upregulated in mesangial cells under diabetic conditions (Refs 160, 161). TGF- $\beta$ is known to upregulate ECM proteins via SMAD transcription factors and mitogen-activated protein kinases (MAPKs) (Refs 162, 163, 164, 165); in addition, recent work has revealed TGF- $\beta$ downregulates the E-box repressor proteins $\delta E F 1$ and SMADinteracting protein 1 (SIP1), which mediate repression of collagen expression at its E-box element (Ref. 166). $\delta E F 1$ can also repress SMAD proteins (Ref. 167).

Several miRNAs, including mir-192, -194, -204, -215 and -216 , are preferentially expressed in the kidney, as compared with other tissues (Ref. 85). Using computational miRNA target predictions from miRNA databases (http://cbio.mskcc.org; http://microrna.sanger.ac.uk/index.shtml) the E-box repressor SIP1 was shown to contain a potential target site for mir-192 and mir-215 regulation.

Using a luciferase reporter system, SIP1 was validated as a target of mir-192 regulation (Table 1), but not of mir-215. TGF- $\beta$ treatment induces mir-192 expression. TGF- $\beta$-induced mir-192 expression or mir-192 transfection can decrease SIP1 levels, while mir-192 inhibitor increases SIP1 levels (Ref. 166). The mechanism of TGF- $\beta$ regulation of mir-192 expression is not completely understood. The mir-192 promoter contains a binding site for the proto-oncogene ETS-1 (Ref. 85), which is also induced by TGF- $\beta$ expression (Ref. 168), representing a possible mechanism of TGF- $\beta$ regulation of mir-192 expression.

mir-192 overexpression leads to repression of translation of its target SIP1, thereby increasing levels of collagen expression. Repression of $\delta E F 1$ using short hairpin RNA (shRNA; for stable transfection of siRNA) shows similar effects, resulting in increased levels of collagen expression; however, double transfection of a mir-192 mimic and $\delta E F 1$ shRNA shows a much larger increase in collagen expression than either achieved separately, suggesting that these two mechanisms act synergistically in the control of collagen expression (Ref. 166).

In vivo analysis of type 1 and type 2 diabetic mice showed elevated levels of mir-192, TGF- $\beta$ and collagen $1 \alpha 2$ in the renal glomeruli (Ref. 166), suggesting the possible involvement of mir-192mediated collagen expression in the pathogenesis of diabetic nephropathy, or other diabetic complications where TGF- $\beta$ levels are raised.

miRNAs associated with diabetic heart

Cardiovascular disease is the principal cause of death in more than $60 \%$ of diabetic cases, with an annual mortality of approximately $5.4 \%$, thereby decreasing life expectancy by up to 10 years (Refs 169, 170). For diabetic patients, the most prominent cardiac electrical disturbance is an abnormal QT interval, which is associated with increased risk of sudden cardiac death (Refs 171, 172). QT interval is the total duration for ventricular depolarisation and repolarisation of cardiac myocytes, which is controlled by the flow of inward and outward ion currents. Increasing inward currents and/or decreasing outward currents lead to prolonged QT interval. The outward currents occur via a number of $\mathrm{K}^{+}$ channels.

Human ether-a-go-go related gene (HERG) encodes one of these channels - the rapid delayed rectifier $\mathrm{K}^{+}$current channel $\left(\mathrm{I}_{\mathrm{Kr}}\right)$. HERG is downregulated in diabetic hearts, thereby contributing to slowed repolarisation and prolonged QT interval (Refs 173, 174). HERG expression is downregulated at the posttranscriptional level: HERG mRNA levels remain constant, while HERG protein levels are reduced 
by $60 \%$ in diabetic heart as compared with nondiabetic/control heart (Refs 173, 174, 175).

mir- 1 and mir-133 are specifically expressed in adult cardiac and skeletal muscle tissues, and upregulated in rabbit diabetic heart tissue and also in ventricular samples from human diabetic patients (Refs 104, 176). Using a luciferase reporter plasmid and western blotting, HERG mRNA was shown to be a target of mir-133 action (Table 1), while mir-1 had no effect on HERG expression (Ref. 175). $\mathrm{I}_{\mathrm{Kr}}$, the channel for rapid delayed rectifier $\mathrm{K}^{+}$ current, was shown to be underexpressed in diabetic hearts and healthy hearts transfected with mir-133, while transfection of a mir-133 inhibitor AMO-133 partially rectified the depression of $\mathrm{I}_{\mathrm{Kr}}$ in diabetic hearts, and completely rectified expression of $\mathrm{I}_{\mathrm{Kr}}$ in mir133-transfected healthy hearts (Ref. 175).

Serum response factor (SRF) is a cardiac transcription factor highly overexpressed in diabetic hearts (Ref. 175). SRF is essential for expression of mir-1 and mir-133 (Refs 104, 176). SRF siRNA or the SRF inhibitor distamycin reduced expression of mir-1 and mir-133 in diabetic cardiac myocytes. Transfection of SRF siRNA into cardiac myocytes of diabetic hearts resulted in increased levels of $\mathrm{I}_{\mathrm{Kr}}$ expression (Ref. 175). It still remains to be seen whether use of AMO-133 or SRF siRNA in vivo increases $I_{\mathrm{Kr}}$ expression sufficiently to correct or reduce prolonged QT interval in diabetic subjects.

mir-133 is also known to repress expression of KCNQ1, which is involved in the formation of the slow delayed rectifier $\mathrm{K}^{+}$current channel $\left(\mathrm{I}_{\mathrm{Ks}}\right)$ (Ref. 177), although it is currently unknown whether this channel plays a role in the development of long QT syndrome in diabetic patients.

\section{Clinical implications/applications}

Until recently, miRNAs had not been considered as classical therapeutic targets, as they do not code for proteins. Initial studies aimed at exploiting miRNAs as a form of therapy have shown promising results. Following intravenous injection of modified antisense oligonucleotides (termed antagomirs) into mice, in vivo inhibition of four miRNAs - mir-16, mir-122, mir-192 and mir-194 - has been successfully demonstrated (Ref. 96). This approach resulted not only in blockage of target miRNAs, but also in their degradation in most organs analysed, including liver, kidney, heart, lung, intestine, bone marrow, muscle, skin, fat, ovaries and adrenals. Lack of effect observed in brain is possibly due to restricted diffusion of charged nucleic acids across the blood-brain barrier. Alternative approaches to targeting miRNAs therapeutically by inhibiting Drosha, Dicer or other miRNA pathway components are being investigated. Conversely, where reduced miRNA expressed is associated with a disease phenotype and increased expression of relevant miRNA could be of potential therapeutic relevance to rescue disease phenotype, introduction of miRNA mimics is being investigated. However, suitable expression vectors have yet to be identified for the safe delivery and maintenance of such effects long-term (Ref. 178).

\section{Research in progress and outstanding research questions}

The importance of miRNAs in normal and pathological conditions is still being realised. Recent studies have clearly indicated an association between dysregulated expression of these short RNAs in regulated and defective insulin secretion from $\beta$-cells and in diabetic kidney and heart disease. Recently, overexpression of a specific miRNA (mir-29) which is upregulated in diabetic rats - has been found to have a functional role in insulin resistance (Ref. 179) and, furthermore, analysis of murine pancreas development has indicated a unique miRNA profile to be necessary during pancreas development for generation of normal $\beta$-cells (Ref. 180). So, while studies associating miRNAs with diabetes are so far limited in numbers, they suggest important roles for miRNAs as potential biomarkers and possibly therapeutic targets. More extensive studies investigating the expression and functional relevance of miRNAs in both type 1 and type 2 diabetes will undoubtedly increase our understanding of these complex conditions and will hopefully aid in the identification of novel therapeutic targets and interventions.

\section{Acknowledgements and funding}

The authors acknowledge support from Ireland's Higher Educational Authority Programme for Research in Third Level Institutes (PRTLI) Cycle 3, the Health Research Board, and Dublin City University's Research Fellowship Award. 


\section{References}

1 Bartel, D.P. and Chen, C.Z. (2004) Micromanagers of gene expression: the potentially widespread influence of metazoan microRNAs. Nat Rev Genet 5, 396-400

2 Zamore, P.D. (2004) Plant RNAi: how a viral silencing suppressor inactivates siRNA. Curr Biol 14, R198-200

3 Kumar, A. (2008) RNA interference: a multifaceted innate antiviral defense. Retrovirology 5, 17

4 Lau, N.C. et al. (2001) An abundant class of tiny RNAs with probable regulatory roles in Caenorhabditis elegans. Science 294, 858-862

5 He, L. et al. (2005) A microRNA polycistron as a potential human oncogene. Nature 435 , 828-833

6 Bartel, D.P. (2004) MicroRNAs: genomics, biogenesis, mechanism, and function. Cell 116, 281-297

7 Brennecke, J. et al. (2005) Principles of microRNAtarget recognition. PLoS Biol 3, e85

8 Leung, A.K. and Sharp, P.A. (2007) microRNAs: a safeguard against turmoil? Cell 130, 581-585

9 Lim, L.P. et al. (2005) Microarray analysis shows that some microRNAs downregulate large numbers of target mRNAs. Nature 433, 769-773

10 Lim, L.P. et al. (2003) Vertebrate microRNA genes. Science 299, 1540

11 Zamore, P.D. and Haley, B. (2005) Ribo-gnome: the big world of small RNAs. Science 309, 1519-1524

12 Rajewsky, N. (2006) microRNA target predictions in animals. Nat Genet 38 Suppl, S8-13

13 Lee, R.C., Feinbaum, R.L. and Ambros, V. (1993) The $\mathrm{C}$. elegans heterochronic gene lin-4 encodes small RNAs with antisense complementarity to lin-14. Cell 75, 843-854

14 Ha, I., Wightman, B. and Ruvkun, G. (1996) A bulged lin-4/lin-14 RNA duplex is sufficient for Caenorhabditis elegans lin-14 temporal gradient formation. Genes Dev 10, 3041-3050

15 Olsen, P.H. and Ambros, V. (1999) The lin-4 regulatory RNA controls developmental timing in Caenorhabditis elegans by blocking LIN-14 protein synthesis after the initiation of translation. Dev Biol 216, 671-680

16 Reinhart, B.J. et al. (2000) The 21-nucleotide let-7 RNA regulates developmental timing in Caenorhabditis elegans. Nature 403, 901-906

17 Slack, F.J. et al. (2000) The lin-41 RBCC gene acts in the $\mathrm{C}$. elegans heterochronic pathway between the let-7 regulatory RNA and the LIN-29 transcription factor. Mol Cell 5, 659-669
18 Lin, S.Y. et al. (2003) The C elegans hunchback homolog, hbl-1, controls temporal patterning and is a probable microRNA target. Dev Cell 4, 639-650

19 Vella, M.C. et al. (2004) The C. elegans microRNA let-7 binds to imperfect let-7 complementary sites from the lin-41 3'UTR. Genes Dev 18, 132-137

20 Takuno, S. and Innan, H. (2008) Evolution of complexity in miRNA-mediated gene regulation systems. Trends Genet 24, 56-59

21 Blow, M.J. et al. (2006) RNA editing of human microRNAs. Genome Biol 7, R27

22 Lee, Y. et al. (2004) MicroRNA genes are transcribed by RNA polymerase II. EMBO J 23, 4051-4060

23 Borchert, G.M., Lanier, W. and Davidson, B.L. (2006) RNA polymerase III transcribes human microRNAs. Nat Struct Mol Biol 13, 1097-1101

24 Cai, X., Hagedorn, C.H. and Cullen, B.R. (2004) Human microRNAs are processed from capped, polyadenylated transcripts that can also function as mRNAs. RNA 10, 1957-1966

25 Denli, A.M. et al. (2004) Processing of primary microRNAs by the Microprocessor complex. Nature 432, 231-235

26 Gregory, R.I. et al. (2004) The Microprocessor complex mediates the genesis of microRNAs. Nature 432, 235-240

27 Han, J. et al. (2004) The Drosha-DGCR8 complex in primary microRNA processing. Genes Dev 18, 3016-3027

28 Lee, Y. et al. (2003) The nuclear RNase III Drosha initiates microRNA processing. Nature 425, 415-419

29 Ruby, J.G., Jan, C.H. and Bartel, D.P. (2007) Intronic microRNA precursors that bypass Drosha processing. Nature $448,83-86$

30 Jiang, F. et al. (2005) Dicer-1 and R3D1-L catalyze microRNA maturation in Drosophila. Genes Dev $19,1674-1679$

31 Chendrimada, T.P. et al. (2005) TRBP recruits the Dicer complex to Ago2 for microRNA processing and gene silencing. Nature 436, 740-744

32 Saito, K. et al. (2005) Processing of pre-microRNAs by the Dicer-1-Loquacious complex in Drosophila cells. PLoS Biol 3, e235

33 Gregory, R.I. et al. (2005) Human RISC couples microRNA biogenesis and posttranscriptional gene silencing. Cell 123, 631-640

34 Maniataki, E. and Mourelatos, Z. (2005) A human, ATP-independent, RISC assembly machine fueled by pre-miRNA. Genes Dev 19, 2979-2990

35 Nykanen, A., Haley, B. and Zamore, P.D. (2001) ATP requirements and small interfering RNA structure in the RNA interference pathway. Cell $107,309-321$ 
36 Cook, H.A. et al. (2004) The Drosophila SDE3 homolog armitage is required for oskar mRNA silencing and embryonic axis specification. Cell 116, 817-829

37 Mourelatos, Z. et al. (2002) miRNPs: a novel class of ribonucleoproteins containing numerous microRNAs. Genes Dev 16, 720-728

38 Pillai, R.S., Artus, C.G. and Filipowicz, W. (2004) Tethering of human Ago proteins to mRNA mimics the miRNA-mediated repression of protein synthesis. RNA 10, 1518-1525

39 Caudy, A.A. et al. (2002) Fragile X-related protein and VIG associate with the RNA interference machinery. Genes Dev 16, 2491-2496

40 Caudy, A.A. et al. (2003) A micrococcal nuclease homologue in RNAi effector complexes. Nature 425, 411-414

41 Hwang, H.W., Wentzel, E.A. and Mendell, J.T. (2007) A hexanucleotide element directs microRNA nuclear import. Science 315, 97-100

42 Zeng, Y., Yi, R. and Cullen, B.R. (2003) MicroRNAs and small interfering RNAs can inhibit mRNA expression by similar mechanisms. Proc Natl Acad Sci U S A 100, 9779-9784

43 Bagga, S. et al. (2005) Regulation by let-7 and lin-4 miRNAs results in target mRNA degradation. Cell $122,553-563$

44 Jing, Q. et al. (2005) Involvement of microRNA in AU-rich element-mediated mRNA instability. Cell $120,623-634$

45 Giraldez, A.J. et al. (2006) Zebrafish MiR-430 promotes deadenylation and clearance of maternal mRNAs. Science 312, 75-79

46 Humphreys, D.T. et al. (2005) MicroRNAs control translation initiation by inhibiting eukaryotic initiation factor $4 \mathrm{E} /$ cap and poly(A) tail function. Proc Natl Acad Sci U S A 102, 16961-16966

47 Wang, B. et al. (2006) Recapitulation of short RNAdirected translational gene silencing in vitro. Mol Cell 22, 553-560

48 Mathonnet, G. et al. (2007) MicroRNA inhibition of translation initiation in vitro by targeting the cap-binding complex eIF4F. Science 317, 1764-1767

49 Wakiyama, M. et al. (2007) Let-7 microRNAmediated mRNA deadenylation and translational repression in a mammalian cell-free system. Genes Dev 21, 1857-1862

50 Pillai, R.S. et al. (2005) Inhibition of translational initiation by Let-7 MicroRNA in human cells. Science 309, 1573-1576
51 Kiriakidou, M. et al. (2007) An mRNA m7G cap binding-like motif within human Ago2 represses translation. Cell 129, 1141-1151

52 Chendrimada, T.P. et al. (2007) MicroRNA silencing through RISC recruitment of eIF6. Nature 447, 823-828

53 Petersen, C.P. et al. (2006) Short RNAs repress translation after initiation in mammalian cells. Mol Cell 21, 533-542

54 Seggerson, K., Tang, L. and Moss, E.G. (2002) Two genetic circuits repress the Caenorhabditis elegans heterochronic gene lin-28 after translation initiation. Dev Biol 243, 215-225

55 Behm-Ansmant, I. et al. (2006) mRNA degradation by miRNAs and GW182 requires both CCR4:NOT deadenylase and DCP1:DCP2 decapping complexes. Genes Dev 20, 1885-1898

56 Sen, G.L. and Blau, H.M. (2005) Argonaute 2/RISC resides in sites of mammalian mRNA decay known as cytoplasmic bodies. Nat Cell Biol 7, 633-636

57 Liu, J. et al. (2005) MicroRNA-dependent localization of targeted mRNAs to mammalian P-bodies. Nat Cell Biol 7, 719-723

58 Jakymiw, A. et al. (2005) Disruption of GW bodies impairs mammalian RNA interference. Nat Cell Biol 7, 1267-1274

59 Meister, G. et al. (2005) Identification of novel argonaute-associated proteins. Curr Biol 15, 2149-2155

60 Parker, R. and Song, H. (2004) The enzymes and control of eukaryotic mRNA turnover. Nat Struct Mol Biol 11, 121-127

61 Pillai, R.S., Bhattacharyya, S.N. and Filipowicz, W. (2007) Repression of protein synthesis by miRNAs: how many mechanisms? Trends Cell Biol 17, 118-126

62 Schmitter, D. et al. (2006) Effects of Dicer and Argonaute down-regulation on mRNA levels in human HEK293 cells. Nucleic Acids Res 34, 4801-4815

63 Rehwinkel, J. et al. (2005) A crucial role for GW182 and the DCP1:DCP2 decapping complex in miRNAmediated gene silencing. RNA 11, 1640-1647

64 Brengues, M., Teixeira, D. and Parker, R. (2005) Movement of eukaryotic mRNAs between polysomes and cytoplasmic processing bodies. Science 310, 486-489

65 Vasudevan, S. and Steitz, J.A. (2007) AU-richelement-mediated upregulation of translation by FXR1 and Argonaute 2. Cell 128, 1105-1118

66 Vasudevan, S., Tong, Y. and Steitz, J.A. (2007) Switching from repression to activation: 
microRNAs can up-regulate translation. Science 318, 1931-1934

67 Vasudevan, S., Tong, Y. and Steitz, J.A. (2008) Cell-cycle control of microRNA-mediated translation regulation. Cell Cycle 7, 1545-1549

68 Jopling, C.L. et al. (2005) Modulation of hepatitis C virus RNA abundance by a liver-specific MicroRNA. Science 309, 1577-1581

69 Yoon, S. and De Micheli, G. (2006) Computational identification of microRNAs and their targets. Birth Defects Res C Embryo Today 78, 118-128

70 Bentwich, I. et al. (2005) Identification of hundreds of conserved and nonconserved human microRNAs. Nat Genet 37, 766-770

71 Kiriakidou, M. et al. (2004) A combined computational-experimental approach predicts human microRNA targets. Genes Dev 18, 1165-1178

72 Lewis, B.P. et al. (2003) Prediction of mammalian microRNA targets. Cell 115, 787-798

73 Farh, K.K. et al. (2005) The widespread impact of mammalian MicroRNAs on mRNA repression and evolution. Science 310, 1817-1821

74 Bentwich, I. (2005) Prediction and validation of microRNAs and their targets. FEBS Lett 579, 5904-5910

75 Stark, A. et al. (2005) Animal MicroRNAs confer robustness to gene expression and have a significant impact on 3'UTR evolution. Cell 123, 1133-1146

76 Sood, P. et al. (2006) Cell-type-specific signatures of microRNAs on target mRNA expression. Proc Natl Acad Sci U S A 103, 2746-2751

77 Maziere, P. and Enright, A.J. (2007) Prediction of microRNA targets. Drug Discov Today 12, $452-458$

78 Zilberstein, C.B. et al. (2006) A high-throughput approach for associating MicroRNAs with their activity conditions. J Comput Biol 13, 245-266

79 Berezikov, E., Cuppen, E. and Plasterk, R.H. (2006) Approaches to microRNA discovery. Nat Genet 38 Suppl, S2-7

80 Krichevsky, A.M. et al. (2003) A microRNA array reveals extensive regulation of microRNAs during brain development. RNA 9, 1274-1281

81 Babak, T. et al. (2004) Probing microRNAs with microarrays: tissue specificity and functional inference. RNA 10, 1813-1819

82 Barad, O. et al. (2004) MicroRNA expression detected by oligonucleotide microarrays: system establishment and expression profiling in human tissues. Genome Res 14, 2486-2494
83 Liu, C.G. et al. (2004) An oligonucleotide microchip for genome-wide microRNA profiling in human and mouse tissues. Proc Natl Acad Sci U S A 101, 9740-9744

84 Miska, E.A. et al. (2004) Microarray analysis of microRNA expression in the developing mammalian brain. Genome Biol 5, R68

85 Sun, Y. et al. (2004) Development of a micro-array to detect human and mouse microRNAs and characterization of expression in human organs. Nucleic Acids Res 32, e188

86 Thomson, J.M. et al. (2004) A custom microarray platform for analysis of microRNA gene expression. Nat Methods 1, 47-53

87 Baskerville, S. and Bartel, D.P. (2005) Microarray profiling of microRNAs reveals frequent coexpression with neighboring miRNAs and host genes. RNA 11, 241-247

88 Monticelli, S. et al. (2005) MicroRNA profiling of the murine hematopoietic system. Genome Biol 6, R71

89 Shingara, J. et al. (2005) An optimized isolation and labeling platform for accurate microRNA expression profiling. RNA 11, 1461-1470

90 Wienholds, E. et al. (2005) MicroRNA expression in zebrafish embryonic development. Science 309, 310-311

91 Castoldi, M. et al. (2006) A sensitive array for microRNA expression profiling (miChip) based on locked nucleic acids (LNA). RNA 12, 913-920

92 Nelson, P.T. et al. (2004) Microarray-based, highthroughput gene expression profiling of microRNAs. Nat Methods 1, 155-161

$93 \mathrm{Lu}$, J. et al. (2005) MicroRNA expression profiles classify human cancers. Nature 435, 834-838

94 Allawi, H.T. et al. (2004) Quantitation of MicroRNAs using a modified Invader assay. RNA 10, 1153-1161

95 Kim, V.N. and Nam, J.W. (2006) Genomics of microRNA. Trends Genet 22, 165-173

96 Krutzfeldt, J. et al. (2005) Silencing of microRNAs in vivo with 'antagomirs'. Nature 438, 685-689

97 Davis, S. et al. (2006) Improved targeting of miRNA with antisense oligonucleotides. Nucleic Acids Res 34, 2294-2304

98 Esau, C. et al. (2006) miR-122 regulation of lipid metabolism revealed by in vivo antisense targeting. Cell Metab 3, 87-98

99 Zhou, H., Huang, C. and Xia, X.G. (2008) A tightly regulated Pol III promoter for synthesis of miRNA genes in tandem. Biochim Biophys Acta, Apr 7 [Epub ahead of print] 
100 Esau, C. et al. (2004) MicroRNA-143 regulates adipocyte differentiation. J Biol Chem 279, 52361-52365

101 Brennecke, J. et al. (2003) bantam encodes a developmentally regulated microRNA that controls cell proliferation and regulates the proapoptotic gene hid in Drosophila. Cell 113, 25-36

102 Krutzfeldt, J. and Stoffel, M. (2006) MicroRNAs: a new class of regulatory genes affecting metabolism. Cell Metab 4, 9-12

103 Chen, C.Z. et al. (2004) MicroRNAs modulate hematopoietic lineage differentiation. Science 303, 83-86

104 Zhao, Y., Samal, E. and Srivastava, D. (2005) Serum response factor regulates a muscle-specific microRNA that targets Hand2 during cardiogenesis. Nature 436, 214-220

105 Poy, M.N. et al. (2004) A pancreatic islet-specific microRNA regulates insulin secretion. Nature 432, 226-230

106 Carthew, R.W. (2006) Gene regulation by microRNAs. Curr Opin Genet Dev 16, 203-208

107 Harfe, B.D. et al. (2005) The RNaseIII enzyme Dicer is required for morphogenesis but not patterning of the vertebrate limb. Proc Natl Acad Sci US A 102, 10898-10903

108 Dostie, J. et al. (2003) Numerous microRNPs in neuronal cells containing novel microRNAs. RNA 9, 180-186

109 Jin, P. et al. (2004) Biochemical and genetic interaction between the fragile $\mathrm{X}$ mental retardation protein and the microRNA pathway. Nat Neurosci 7, 113-117

110 Abelson, J.F. et al. (2005) Sequence variants in SLITRK1 are associated with Tourette's syndrome. Science 310, 317-320

111 Schratt, G.M. et al. (2006) A brain-specific microRNA regulates dendritic spine development. Nature 439, 283-289

112 Calin, G.A. et al. (2004) Human microRNA genes are frequently located at fragile sites and genomic regions involved in cancers. Proc Natl Acad Sci U S A 101, 2999-3004

113 Calin, G.A. et al. (2002) Frequent deletions and down-regulation of micro-RNA genes miR15 and miR16 at 13q14 in chronic lymphocytic leukemia. Proc Natl Acad Sci U S A 99, 15524-15529

114 Stilgenbauer, S. et al. (1998) Expressed sequences as candidates for a novel tumor suppressor gene at band 13q14 in B-cell chronic lymphocytic leukemia and mantle cell lymphoma. Oncogene 16, 1891-1897
115 Johnson, S.M. et al. (2005) RAS is regulated by the let-7 microRNA family. Cell 120, 635-647

116 Costinean, S. et al. (2006) Pre-B cell proliferation and lymphoblastic leukemia/high-grade lymphoma in E(mu)-miR155 transgenic mice. Proc Natl Acad Sci U S A 103, 7024-7029

117 Lecellier, C.H. et al. (2005) A cellular microRNA mediates antiviral defense in human cells. Science 308, 557-560

118 Bennasser, Y. et al. (2005) Evidence that HIV-1 encodes an siRNA and a suppressor of RNA silencing. Immunity 22, 607-619

119 Sullivan, C.S. and Ganem, D. (2005) A virusencoded inhibitor that blocks RNA interference in mammalian cells. J Virol 79, 7371-7379

120 Samols, M.A. et al. (2007) Identification of cellular genes targeted by KSHV-encoded microRNAs. PLoS Pathog 3, e65

121 Sullivan, C.S.etal. (2005) SV40-encoded microRNAs regulate viral gene expression and reduce susceptibility to cytotoxic Tcells. Nature 435, 682-686

122 Cullen, B.R. (2006) Is RNA interference involved in intrinsic antiviral immunity in mammals? Nat Immunol 7, 563-567

123 Pedersen, I.M. et al. (2007) Interferon modulation of cellular microRNAs as an antiviral mechanism. Nature 449, 919-922

124 Nathan, D.M. (1993) Long-term complications of diabetes mellitus. N Engl J Med 328, 1676-1685

125 [No authors listed] (1993) The effect of intensive treatment of diabetes on the development and progression of long-term complications in insulindependent diabetes mellitus. The Diabetes Control and Complications Trial Research Group. N Engl J Med 329, 977-986

126 O'Driscoll, L., Gammell, P. and Clynes, M. (2004) Mechanisms associated with loss of glucose responsiveness in beta cells. Transplant Proc 36, 1159-1162

127 O'Driscoll, L. et al. (2006) Phenotypic and global gene expression profile changes between low passage and high passage MIN-6 cells. J Endocrinol 191, 665-676

128 Dowling, P. et al. (2006) Proteomic screening of glucose-responsive and glucose non-responsive MIN-6 beta cells reveals differential expression of proteins involved in protein folding, secretion and oxidative stress. Proteomics 6, 6578-6587

129 Abderrahmani, A. et al. (2006) Mechanisms controlling the expression of the components of the exocytotic apparatus under physiological and pathological conditions. Biochem Soc Trans 34, 696-700 
130 Dunn, W. et al. (2005) Human cytomegalovirus expresses novel microRNAs during productive viral infection. Cell Microbiol 7, 1684-1695

131 Yamakuni, T. et al. (2002) V-1, a catecholamine biosynthesis regulatory protein, positively controls catecholamine secretion in PC12D cells. FEBS Lett 530, 94-98

132 Antonin, W., Riedel, D. and von Mollard, G.F. (2000) The SNARE Vtila-beta is localized to small synaptic vesicles and participates in a novel SNARE complex. J Neurosci 20, 5724-5732

133 Taoka, M. et al. (2003) V-1, a protein expressed transiently during murine cerebellar development, regulates actin polymerization via interaction with capping protein. J Biol Chem 278, 5864-5870

134 Hammar, E.B. et al. (2005) Activation of NF-kappaB by extracellular matrix is involved in spreading and glucose-stimulated insulin secretion of pancreatic beta cells. J Biol Chem 280, 30630-30637

135 Norlin, S., Ahlgren, U. and Edlund, H. (2005) Nuclear factor-\{kappa\}B activity in \{beta\}-cells is required for glucose-stimulated insulin secretion. Diabetes 54, 125-132

136 Krek, A. et al. (2005) Combinatorial microRNA target predictions. Nat Genet 37, 495-500

137 Kloosterman, W.P. et al. (2007) Targeted inhibition of miRNA maturation with morpholinos reveals a role for miR-375 in pancreatic islet development. PLoS Biol 5, e203

138 Baroukh, N. et al. (2007) MicroRNA-124a regulates Foxa2 expression and intracellular signaling in pancreatic beta-cell lines. J Biol Chem 282, 19575-19588

139 Enright, A.J. et al. (2003) MicroRNA targets in Drosophila. Genome Biol 5, R1

140 Zhang, X. et al. (2005) Genome-wide analysis of cAMP-response element binding protein occupancy, phosphorylation, and target gene activation in human tissues. Proc Natl Acad Sci U S A 102, 4459-4464

$141 \mathrm{Wu}, \mathrm{K} . \mathrm{L}$. et al. (1997) Hepatocyte nuclear factor 3beta is involved in pancreatic beta-cell-specific transcription of the pdx-1 gene. Mol Cell Biol 17, 6002-6013

142 Lee, C.S. et al. (2002) Foxa2 controls Pdx1 gene expression in pancreatic beta-cells in vivo. Diabetes 51, 2546-2551

143 Jonsson, J. et al. (1994) Insulin-promoter-factor 1 is required for pancreas development in mice. Nature 371, 606-609

144 Offield, M.F. et al. (1996) PDX-1 is required for pancreatic outgrowth and differentiation of the rostral duodenum. Development 122, 983-995
145 Stoffers, D.A. et al. (1997) Pancreatic agenesis attributable to a single nucleotide deletion in the human IPF1 gene coding sequence. Nat Genet 15, 106-110

146 Lantz, K.A. et al. (2004) Foxa2 regulates multiple pathways of insulin secretion. J Clin Invest 114, 512-520

147 Meissner, T., Beinbrech, B. and Mayatepek, E. (1999) Congenital hyperinsulinism: molecular basis of a heterogeneous disease. Hum Mutat 13, 351-361

148 Kasai, K. et al. (2005) Rab27a mediates the tight docking of insulin granules onto the plasma membrane during glucose stimulation. J Clin Invest 115, 388-396

149 Lovis, P., Gattesco, S. and Regazzi, R. (2008) Regulation of the expression of components of the exocytotic machinery of insulin-secreting cells by microRNAs. Biol Chem 389, 305-312

150 Lagos-Quintana, M. et al. (2002) Identification of tissue-specific microRNAs from mouse. Curr Biol 12, 735-739

151 Landgraf, P. et al. (2007) A mammalian microRNA expression atlas based on small RNA library sequencing. Cell 129, 1401-1414

152 Plaisance, V. et al. (2006) MicroRNA-9 controls the expression of Granuphilin/Slp4 and the secretory response of insulin-producing cells. J Biol Chem 281, 26932-26942

153 Wang, J. et al. (1999) Novel rabphilin-3-like protein associates with insulin-containing granules in pancreatic beta cells. J Biol Chem 274, 28542-28548

154 Torii, S. et al. (2004) Rab27 effector granuphilin promotes the plasma membrane targeting of insulin granules via interaction with syntaxin 1 a. J Biol Chem 279, 22532-22538

155 Gomi, H. et al. (2005) Granuphilin molecularly docks insulin granules to the fusion machinery. J Cell Biol 171, 99-109

156 Coppola, T. et al. (2002) Pancreatic beta-cell protein granuphilin binds Rab3 and Munc-18 and controls exocytosis. Mol Biol Cell 13, 1906-1915

157 Torii, S. et al. (2002) Granuphilin modulates the exocytosis of secretory granules through interaction with syntaxin 1a. Mol Cell Biol 22, 5518-5526

158 Schleicher, E.D. and Olgemoller, B. (1992) Glomerular changes in diabetes mellitus. Eur J Clin Chem Clin Biochem 30, 635-640

159 Ziyadeh, F.N. (1993) The extracellular matrix in diabetic nephropathy. Am J Kidney Dis 22, 736-744 
160 Reeves, W.B. and Andreoli, T.E. (2000)

Transforming growth factor beta contributes to progressive diabetic nephropathy. Proc Natl Acad Sci U S A 97, 7667-7669

161 Sharma, K. and Ziyadeh, F.N. (1995)

Hyperglycemia and diabetic kidney disease. The case for transforming growth factor-beta as a key mediator. Diabetes 44, 1139-1146

162 Poncelet, A.C. and Schnaper, H.W. (2001) Sp1 and Smad proteins cooperate to mediate transforming growth factor-beta 1-induced alpha 2(I) collagen expression in human glomerular mesangial cells. J Biol Chem 276, 6983-6992

163 Tsuchida, K. et al. (2003) Role of Smad4 on TGFbeta-induced extracellular matrix stimulation in mesangial cells. Kidney Int 63, 2000-2009

164 Chin, B.Y. et al. (2001) Stimulation of proalpha(1)(I) collagen by TGF-beta(1) in mesangial cells: role of the p38 MAPK pathway. Am J Physiol Renal Physiol 280, F495-504

165 Hayashida, T. et al. (1999) TGF-beta1 activates MAP kinase in human mesangial cells: a possible role in collagen expression. Kidney Int 56, 1710-1720

166 Kato, M. et al. (2007) MicroRNA-192 in diabetic kidney glomeruli and its function in TGF-betainduced collagen expression via inhibition of E-box repressors. Proc Natl Acad Sci U S A 104, 3432-3437

167 Postigo, A.A. (2003) Opposing functions of ZEB proteins in the regulation of the TGFbeta/BMP signaling pathway. EMBO J 22, 2443-2452

168 Liu, S. et al. (2005) ERK-dependent signaling pathway and transcriptional factor Ets-1 regulate matrix metalloproteinase- 9 production in transforming growth factor-beta1 stimulated glomerular podocytes. Cell Physiol Biochem 16, 207-216

169 Donnelly, R. et al. (2000) ABC of arterial and venous disease: vascular complications of diabetes. BMJ 320, 1062-1066

170 Duncan, C. et al. (1992) An audit of non-insulindependent diabetics attending a district general hospital diabetic clinic: implications for shared care between hospital and general practice. Health Bull (Edinb) 50, 302-308

171 Casis, O. and Echevarria, E. (2004) Diabetic cardiomyopathy: electromechanical cellular alterations. Curr Vasc Pharmacol 2, 237-248

172 Veglio, M., Chinaglia, A. and Cavallo-Perin, P. (2004) QT interval, cardiovascular risk factors and risk of death in diabetes. J Endocrinol Invest 27, 175-181

173 Zhang, Y. et al. (2007) Ionic mechanisms underlying abnormal QT prolongation and the associated arrhythmias in diabetic rabbits: a role of rapid delayed rectifier $\mathrm{K}+$ current. Cell Physiol Biochem 19, 225-238

174 Zhang, Y. et al. (2006) Restoring depressed HERG $\mathrm{K}+$ channel function as a mechanism for insulin treatment of abnormal QT prolongation and associated arrhythmias in diabetic rabbits. Am J Physiol Heart Circ Physiol 291, H1446-1455

175 Xiao, J. et al. (2007) MicroRNA miR-133 represses HERG K+ channel expression contributing to QT prolongation in diabetic hearts. J Biol Chem 282, 12363-12367

176 Chen, J.F. et al. (2006) The role of microRNA-1 and microRNA-133 in skeletal muscle proliferation and differentiation. Nat Genet 38, 228-233

177 Luo, X. et al. (2007) Transcriptional activation by stimulating protein 1 and post-transcriptional repression by muscle-specific microRNAs of IKsencoding genes and potential implications in regional heterogeneity of their expressions. J Cell Physiol 212, 358-367

178 Esau, C.C. and Monia, B.P. (2007) Therapeutic potential for microRNAs. Adv Drug Deliv Rev 59, 101-114

$179 \mathrm{He}, \mathrm{A}$. et al. (2007) Overexpression of micro ribonucleic acid 29, highly up-regulated in diabetic rats, leads to insulin resistance in 3T3-L1 adipocytes. Mol Endocrinol 21, 2785-2794

180 Lynn, F.C. et al. (2007) MicroRNA expression is required for pancreatic islet cell genesis in the mouse. Diabetes 56, 2983-2945 


\section{Further reading, resources and contacts}

Websites of the Computational Biology Center of the Memorial Sloan-Kettering Cancer Center, New York, USA, provide a range of bioinformatic tools, including a searchable database for predicted miRNA targets and expression:

http://cbio.mskcc.org

http://www.microrna.org/microrna/home.do

MiRBase of the Wellcome Trust Sanger Institute, Cambridge, UK, provides data previously accessible from the miRNA Registry and is a searchable database of published miRNA sequences and annotation. The miRBase Target database is a new resource at this site for predicted miRNA targets in animals:

http://microrna.sanger.ac.uk/sequences/

The Ambion/Applied Biosystems website provides an excellent miRNA resource page, detailing miRNA processing, function, expression and targets. Ambion/Applied Biosystems also provide all reagents required for miRNA isolation, miRNA RT-PCR, and miRNA functional analysis, by use of $\mathrm{Pre} \mathrm{mir}^{\mathrm{TM}}$ miRNA precusors or Anti-mir ${ }^{\mathrm{TM}}$ miRNA inhibitors:

http://www.ambion.com

\section{Features associated with this article}

\section{Figures}

Figure 1. miRNA biogenesis and target mRNA regulation.

Figure 2. Proposed mechanisms of miRNA action.

Figure 3. Co-ordinated regulation of insulin exocytosis by miRNAs.

Table

Table 1. miRNAs implicated in $\beta$-cell insulin secretion and diabetic complications, and their mRNA targets.

\section{Citation details for this article}

Erica Hennessy and Lorraine O'Driscoll (2008) Molecular medicine of microRNAs: structure, function and implications for diabetes. Expert Rev. Mol. Med. Vol. 10, e24, August 2008, doi:10.1017/ S1462399408000781 